\title{
Coagulation and Fibrinolytic Mechanisms During and after Normal Childbirth
}

JOHN BONNAR,* M.B., M.R.C.o.G. ; G. P. McNICOL, $\dagger$ M.D., PH.D., F.R.C.P. (ED., GLASG.)

A. S. DOUGLAS, $\ddagger$ M.D., F.R.C.P. (LOND., ED., GLASG.)

British Medical fournal, 1970, 2, 200-203

\begin{abstract}
Cummary: A detailed sequential study of the coagulation $\checkmark$ and fibrinolytic systems in 15 healthy women during normal childbirth showed that striking changes in keeping with activation of the clotting mechanism take place during and after placental separation. Shortening of the clotting-test results, a sharp increase of factors VIII and $V$, and a decrease of the plasma fibrinogen were found as the placenta separated. Within one hour of normal delivery the levels of fibrin/fibrinogen degradation products increased and fibrinolytic activity returned to normal non-pregnant levels. In the early puerperium a secondary increase took place in the plasma fibrinogen level, factor VIII remained raised, and the platelet count showed a pronounced rise; these changes may explain the increased predisposition to thromboembolic complications in the puerperium.
\end{abstract}

\section{Introduction}

Normal pregnancy is accompanied by major changes in the haemostatic mechanism, particularly an increase in the levels of certain coagulation factors-for example, factors VII, VIII, and $\mathrm{X}-$ and fibrinogen and a pronounced decrease in fibrinolytic activity. Parturition presents a serious challenge to the integrity of the vascular compartment, but it has been generally held (Taylor, 1966; Donald, 1969) that contraction of the myometrium-the "living ligatures" of the uterus-is the mechanism which, in the main, controls blood loss at delivery. In other situations where there is injury to the vascular tree an efficient blood coagulation system plays a vital part in achieving effective haemostasis and preserving the blood volume. The purpose of this investigation was to determine the effect of parturition on the haemostatic mechanism by a detailed sequential study of the coagulation and fibrinolytic systems during and after the actual process of normal childbirth and placental separation.

The coagulation and fibrinolytic mechanisms may be in a state of dynamic equilibrium which keeps the vascular compartment intact and patent, the coagulation system laying down fibrin to seal any gaps in the vascular endothelium and the fibrinolytic mechanism removing the deposits of fibrin after they have served their haemostatic function (McNicol and Douglas, 1964). A reflection of in-vivo events may therefore be obtained by simultaneous study of the dual mechanisms of blood coagulation and fibrinolysis.

\section{Patients and Methods}

Fifteen healthy patients with uncomplicated full-term pregnancies were studied, and full and informed consent was given by each patient for specimens of blood to be taken during and following delivery. The timing of the blood samples was as follows: (1) late in the second stage of labour and

\footnotetext{
* First Assistant, Nuffield Department of Obstetrics and Gynaecology, Radcliffe Infirmary, Oxford; formerly Senior Registrar in Obstetrics and Gynaecology, Royal Maternity Hospital and Victoria Infirmary, Glasgow.

† Senior Lecturer, University Department of Medicine, Royal Infirmary, Glasgo w C.4.

¥ Professor of Medicine, University Department of Medicine, Royal Infirmary, Glasgow C.4.
}

when the baby's head was distending the perineum; (2) immediately after delivery of the baby while the placenta was separating in utero-that is, the third stage of labour; (3) within one minute of expulsion of the placenta; (4) 15 minutes after placental delivery; (5) one hour after placental delivery; (6) 24 hours after delivery; and (7) three to five days after delivery.

The blood samples $(16 \mathrm{ml}$.) were taken into plastic syringes from an arm vein with the minimum of venous occlusion: 9 $\mathrm{ml}$. of blood was mixed with $1 \mathrm{ml}$. of $3.8 \%$ sodium citrate in a plastic tube for coagulation and fibrinolytic tests; $5 \mathrm{ml}$. was added to a plastic tube containing glass beads and $1 \mathrm{mg}$. of the synthetic fibrinolytic inhibitor tranexamic acid for assay of fibrin/fibrinogen degradation products; and $2 \mathrm{ml}$. was added to a plastic tube containing edetic acid for platelet counting. The coagulation and fibrinolytic assays were invariably carried out within half an hour of collection of the blood, which was kept at $4^{\circ} \mathrm{C}$. The following assays were performed:

Coagulation System Assays.-Recalcification time in plastic tubes (Biggs and MacFarlane, 1962). Kaolin-cephalin clotting-time (Proctor and Rapaport, 1961). Partial thromboplastin time (Langdell et al., 1953). Factor II (prothrombin) (Owren and Aas, 1951). Factor V (Shanberge et al., 1967). Factor, VIII and IX (Breckenridge and Ratnoff, 1962). Factor X (Denson, 1961). Onestage prothrombin time (Douglas, 1962). Thrombin clotting-time (McNicol and Douglas, 1964). Platelet count (Dacie, 1963).

Fibrinolytic Enzyme System Assays.-Fibrinogen (Ratnoff and Menzie, 1964). Plasminogen (Remmert and Cohen, 1949; McNicol and Douglas, 1964). Euglobulin lysis time (Nilsson and Olow, 1962). Urokinase sensitivity test (McNicol et al., 1965). Fibrin/fibrinogen degradation products (Merskey et al., 1966; Bonnar et al., 1969a).

Statistical Analysis.-As the data comprised measurements on a single group at different times, Wilcoxon's Signed Ranks Test was used to determine the statistical significance of any changes in the coagulation and fibrinolytic assays.

\section{Results}

\section{Coagulation Systems Assays}

The changes recorded in the plasma recalcification time, kaolin-cephalin clotting-time, and partial thromboplastin time during the third stage of labour and after placental delivery are shown in Fig. 1. The recalcification time recorded during the third stage of labour and immediately after placental delivery was significantly shorter than that found in the second stage of labour $(r=0, P<0.002)$, the recalcification time gradually increased after placental delivery and values similar to those obtained in the second stage of labour were again found on the first day of the puerperium. The kaolincephalin clotting-time showed a significant but less dramatic shortening during and immediately after the third stage $(r=6.5, P<0.05)$. The plasma thromboplastin time was significantly shortened in the third stage of labour and immediately after placental delivery $(\mathrm{r}=11.0, \mathrm{P}<0.01)$; within 15 minutes of expulsion of the placenta the pre-delivery values were restored.

The changes in the coagulation factors that occurred before and after delivery are shown in Fig. 2. A sharp increase in factor VIII activity occurred during delivery, the mean factor 


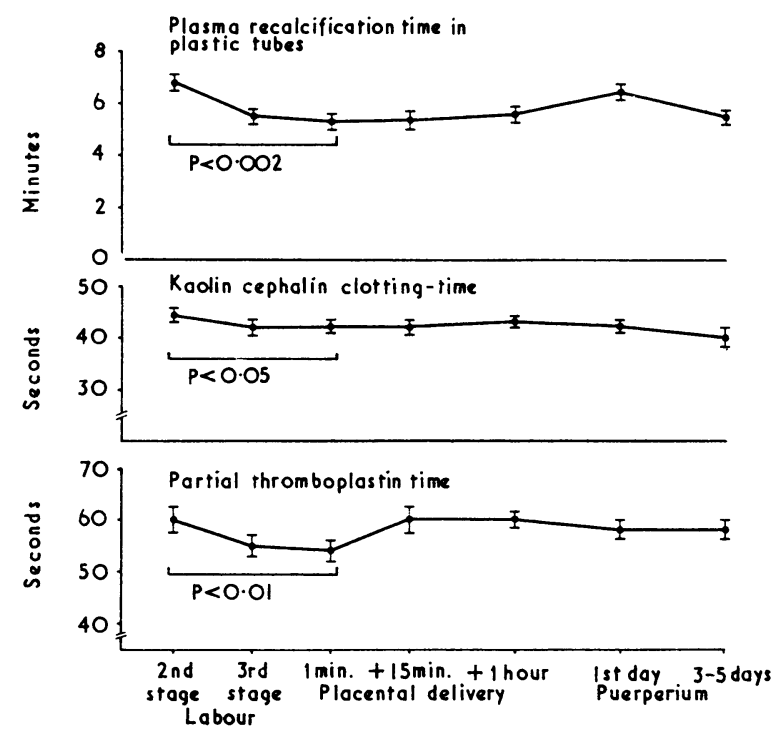

FIG. 1.-Clotting tests during and after normal childbirth. Each point represents the mean of the results in 15 patients (with S.E. of mean).

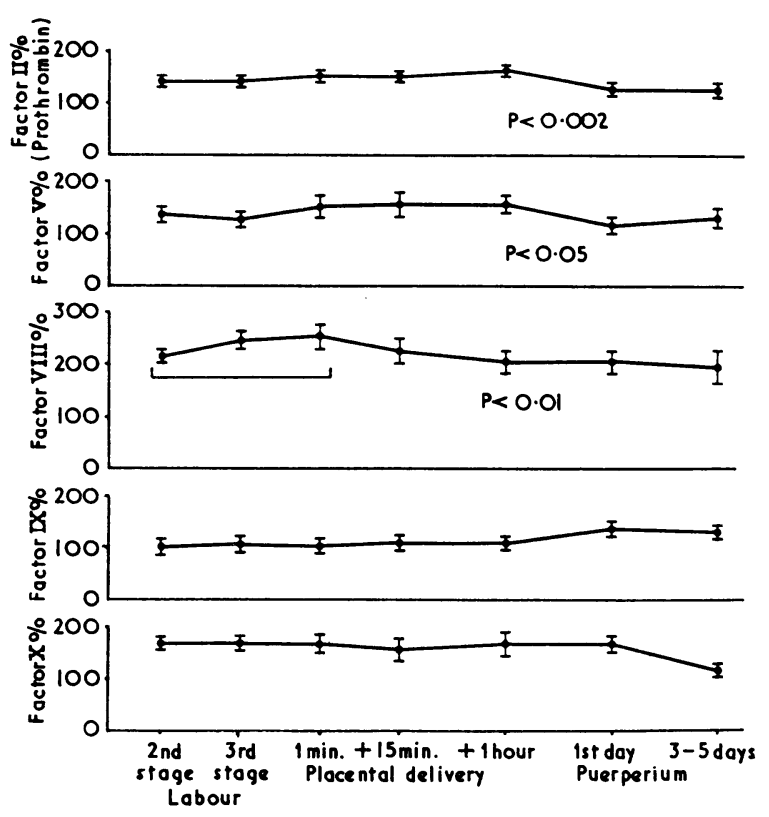

Fig. 2.- Changes in the levels of the coagulation factors during and after normal childbirth. Symbols as in Fig. 1.

VIII level rising from $212 \%$ in the second stage of labour to $251 \%$ immediately after placental delivery $(\mathrm{r}=2.5, \mathrm{P}<0.01)$. The pre-delivery values of factor VIII activity were restored one hour after delivery and the mean level remained around $200 \%$ in the immediate puerperium. The mean level of factor $\mathrm{V}$ increased immediately after placental delivery, and on the first day of the puerperium the levels of factor II (prothrombin) and factor $V$ were significantly lower than during the first hour after placental delivery. A normal level of factor IX activity was recorded in the second stage of labour and after placental delivery but a slight increase of the mean level was found in the early puerperium. Factor $\mathbf{X}$ activity compared with normal non-pregnant values was increased during the second stage of labour with a mean value of $166 \%$ and between the third and fifth day of the puerperium it fell to $112 \%$.

A highly significant increase of the platelet count was evident following delivery, the mean platelet count increasing

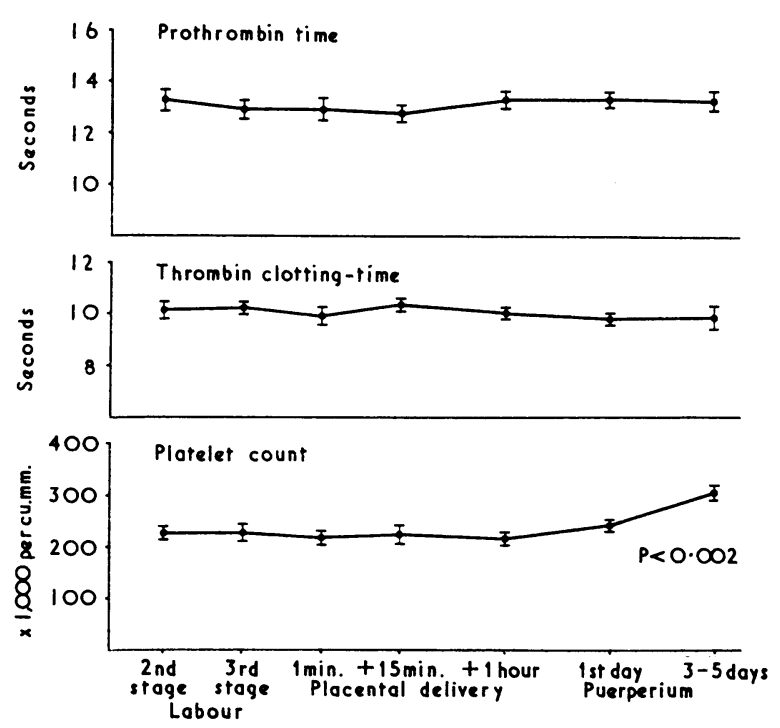

FIG. 3.-Platelet count, prothrombin time, and thrombin clotting-time during and after normal childbirth. Symbols as in Fig. 1.

from $221,000 /$ cu.mm. during the delivery to $304,000 /$ cu.mm. between the third and fifth day of the puerperium $(r=0$, $\mathrm{P}<0.002$ ) (Fig. 3). No significant changes occurred in prothrombin time or thrombin clotting-time during or after delivery.

\section{Fibrinolytic Enzyme System Assays}

The significant decrease of plasma fibrinogen which occurred during the third stage of labour and in the first 15 minutes following delivery of the placenta $(r=0, P<0.002)$ is shown in Fig. 4. The fibrinogen level then gradually increased and was at a higher level three to five days after delivery than during the second stage of labour. The plasminogen level showed a slight but significant decrease during the third stage

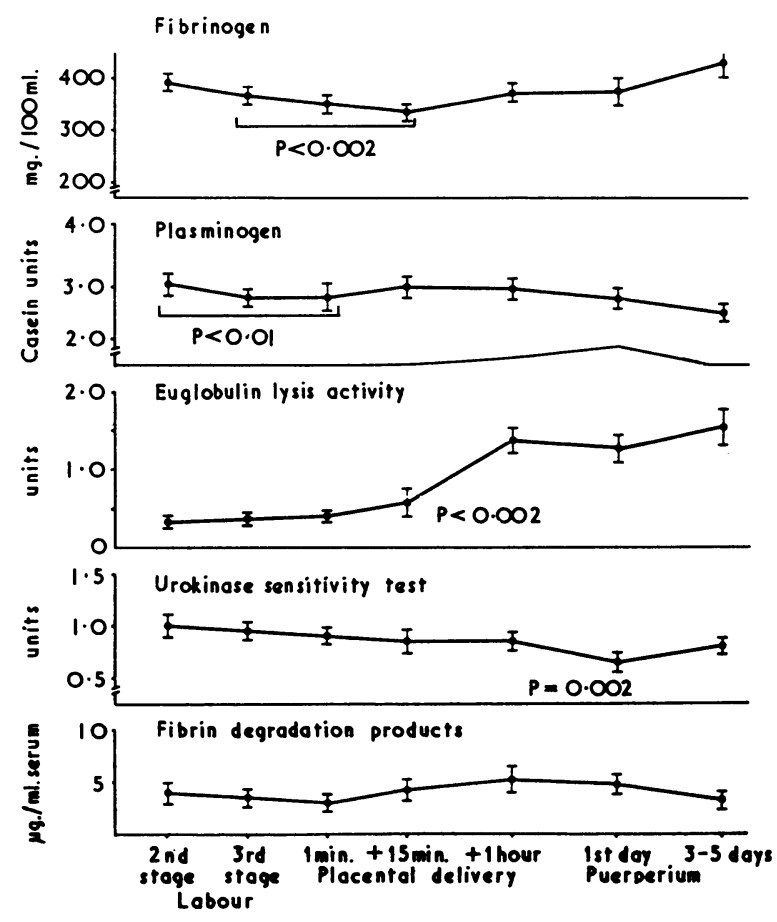

FIG. 4.-Plasma fibrinogen levels and the components of the fibrinolytic enzyme system during and after normal childbirth Symbols as in Fig. 1 . 
of labour and immediately after placental delivery $(r=8.5$, $P<0.01$ ), but no increase of plasminogen was evident in the early puerperium. The changes of fibrinogen and plasminogen during the third stage of labour and immediately after placental delivery showed a significant positive correlation $(\mathrm{r}=+0.327, \mathrm{P}<0.05)$ (Fig. 5).

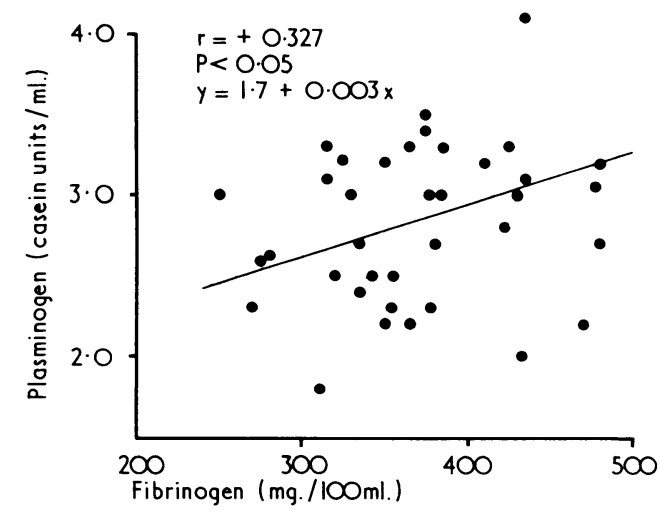

FIG. 5.-Correlation between plasma fibrinogen and plasminogen levels during and immediately after placental separation.

A pronounced inhibition of euglobulin lysis activity was present in the second and third stages of labour and for the first 15 minutes after delivery, but within one hour euglobulin lysis activity was in the normal non-pregnant range and fibrinolytic activity continued in the normal range in the immediate puerperium. The change in the euglobulin lysis activity between 15 minutes and one hour after placental delivery was highly significant $(r=0, P<0.002)$. No change in the level of inhibitors to urokinase-induced lysis was detected until the first day after delivery when a slight but significant increase in the level of urokinase inhibition was present $(r=6.5, P<0.02)$. During the second stage of labour the levels of fibrin/fibrinogen degradation products in the serum were raised but showed a wide range of values $(3.8 \pm 2.9 \mu \mathrm{g} . / \mathrm{ml}$.) and one hour after the delivery the level rose to $5 \cdot 8 \pm 4.7$ $\mu \mathrm{g} . / \mathrm{ml}$. The levels remained raised on the first day of the puerperium and decreased slightly between the third and fifth day.

\section{Discussion}

Haemorrhage occurring during the period of childbirth is frequently associated with uterine atony or soft-tissue laceration, but in these circumstances bleeding is usually readily controlled and is rarely fatal. Though the precise mechanism of haemostasis during normal parturition is still uncertain, fatal obstetric haemorrhage is often accompanied by defective blood clotting. The concentration of plasma fibrinogen and of factors VII and $X$ is increased in late pregnancy (Ratnoff et al., 1954; Pechet and Alexander, 1961; Talbert and Langdell, 1964), and factor VIII activity is also increased (Nossel et al., 1966; Nilsson and Kullander, 1967). Fibrinolytic activity is known to be decreased in late pregnancy and labour and to return to normal in the early puerperium (Biezenski and Moore, 1958; Shaper et al., 1966; Bonnar et al., 1969b). Ratnoff et al. (1954) were unable to show any consistent changes in the clotting tests during normal parturition; the tests performed were the whole-blood clotting-time, thrombin time, plasma fibrinogen, prothrombin assay, and platelet count, and only a few of these were performed on any one patient. The sequential study presented here has shown that striking changes do take place in the coagulation and fibrinolytic systems during the actual process of parturition.
In the coagulation system assays the shortening of the recalcification time, kaolin-cephalin clotting-time, and partial thromboplastin time, and the sharp increase in factors VIII and $\mathrm{V}$ activity in the peripheral blood during and immediately after placental separation suggest that activation of the clotting mechanism takes place during parturition. Further, the significant decrease of fibrinogen levels during and after placental separation would be in keeping with local deposition of fibrin. The decreased levels of factors II and V on the day following delivery may reflect utilization of these factors or their digestion by plasmin. The changes in the fibrinolytic components during and immediately after placental delivery are consistent with fibrinolysis occurring as a response to local fibrin deposition; the plasma plasminogen level decreased during the third stage of labour and after placental delivery, and the level of fibrin/fibrinogen degradation products in the serum increased one hour after childbirth and remained raised in the early puerperium.

Fibrinolytic activity as measured by the euglobulin clot lysis assay remained greatly reduced during the second and third stage of labour, and the sudden change from reduced to normal activity took place between 15 minutes and one hour after delivery. Biezenski and Moore (1958), using a semiquantitative plasma clot lysis method, found that lytic activity returned to normal within three hours of delivery. Shaper et al. (1966) reported that in African women the return to normal fibrinolytic activity occurred as the child was delivered and before the cord was clamped. The mechanism by which fibrinolytic activity abruptly returns to normal within one hour of delivery is unknown. Kawano et al. (1968) showed that placental extracts contain high levels of inhibitors of fibrinolysis, and he suggested that the placenta itself is responsible for the fibrinolytic inhibition which persists until after the placenta is delivered. In simultaneous studies on maternal blood and cord blood taken at birth, while the cord was pulsating, we have found, however, that the umbilical vein returning from the placenta has increased levels of inhibitors but also a very high level of fibrinolytic activity (Bonnar et al., 1970).

The concurrent findings in the blood coagulation and fibrinolytic systems seem therefore to indicate that during parturition the haemostatic mechanism has an important complementary function to the unique process of myometrial coniraction, which by extravascular compression diminishes the blood flow to the placental site. Life-threatening postpartum haemorrhage is a common complication in women severely affected by von Willebrand's disease (Biggs, 1966), especially when the factor VIII level is low and does not increase during pregnancy (Walker and Dormandy, 1968), suggesting that the clotting mechanism has a vital role in preventing blood loss during parturition. Likewise in abruptio placentae, where a pronounced depletion of clotting factors may develop, serious and sometimes fatal haemorrhage from the uterus is not uncommon. The increased levels of clotting factors during normal pregnancy may represent, therefore, a physiological development to provide for the rapid and effective haemostasis which is required during parturition.

It is of interest that in the early puerperium a secondary increase takes place in the level of fibrinogen, factor VIII activity remains well above non-pregnant levels, and the platelet count shows a pronounced rise. During the puerperium the incidence of thromboembolic complications is three to four times greater than during pregnancy (Arthure et al., 1969; Husni et al., 1967). The rapid rise in circulating platelets and the increased levels of fibrinogen and factor VIII, together with the limited physical activity of the mother which follows childbirth, are possible explanations of the predisposition to thrombosis during the puerperium. The abrupt return of normal fibrinolytic activity after delivery may be a protective mechanism to combat this hazard. 
We are grateful to Sir Hector MacLennan and Professor E. M. McGirr for their interest in this work; to the consultant staff of Glasgow Royal Maternity Hospital for their co-operation; to the Medical Research Council and to FBA Pharmaceuticals for financial assistance; and to Mrs. Christine Pidgeon, Mrs. Alison Sandiford, and Mrs. Eileen Cunningham for laboratory assistance.

The work was completed during the tenure by John Bonnar of the Samuel research scholarship of the Royal College of Obstetricians and Gynaecologists.

\section{REFERENCES}

Arthure, H., et al. (1969). Reports on Public Health and Medical Subjects, No. 119, p. 30. London, H.M.S.O.

Biezenski, J. J., and Moore, H. C. (1958) fournal of Clinical Pathology, 11, 306

Biggs, R. (1966). In Treatment of Haemophilia and Other Coagulation Oxford, Blackwell.

Biggs, R. and MacFarlane, R. G. (1962). In Human Blood Coagulation and its Disorders, 3rd ed., p. 384 . Oxford, Blackwell.

Bonnar, J., Davidson J. F., Podgeon, C. F., McNicol, G. P., and Douglas, A. S. (1969a). British Medical fournal, 3, 137.

Bonnar, J., McNicol, G. P., and Douglas, A. S. (1969b). British Medical fournal, 3, 387.

Bonnar, J., McNicol, G. P., and Douglas, A. S. (1970). In press.

Breckenridge, R. T., and Ratnoff, O. D. (1962). Blood, 20, 137.

Dacie, J. V. (1963). Practical Haematology, p. 61. London, Churchill.

Denson, K. W. (1961). Acta Haematologica, 25, 105.

Donald, I. (1969). Practical Obstetric Problems, 4th ed., p. 683. London, Lloyd-Luke Limited.

Douglas, A. S. (1962). Anticoagulant Therapy, p. 279. Oxford, Blackwell.
Husni, E. A., Pena, L. I., and Lenhert, A. E. (1967). American fournal of Obstetrics and Gynecology, 97, 901 .

Kawano, T. Morimoto, K., and Uemura, Y. (1968), Nature, 217, 253. Kawano, T." Morimoto, K., and Uemura, Y. (1968). Nature, 217, 253 of Laboratory and Clinical Medicine, 41, 637 .

McNicol, G. P., Barakat, A. A., and Douglas, A. S. (1965). Scottish Medical fournal, 10, 189.

McNicol, G. P., and Douglas, A. S. (1964). In Recent Advances in Clinical Pathology, Series 4, Edited by S. C. Dyke, p. 187. London, Churchill.

Merskey, C., Kleiner, C. J., and Johnson, A. J. (1966). Blood, 28, 1.

Nilsson, I. M., and Kullander, S. (1967). Acta Obstetrica et Gynecologica Scandinavica, 46, 273.

Nilsson, I. M., and Olow, B. (1962). Acta Chirurgica Scandinavica, 123, 247

Nossel, H. L., Lanzkowsky, P., Levy, S., Mibashan, R. S., and Hansen, J. D. L. (1966). Thrombosis et Diathesis Haemorrhagica, 16, 185.

Owren, P. A., and Aas, K. (1951). Scandinavian fournal of Clinical and Laboratory Investigation, 3, 201

Pechet, L., and Alexander, B. (1961). New England fournal of Medicine 265, 1093.

Proctor, R. R., and Rapaport, S. I. (1961). American fournal of Clinical Pathology, 36, 212.

Ratnoff, O. D., Colopy, J. E., and Pritchard, J. A. (1954). fournal of Laboratory and Clinical Medicine, 44, 408.

Ratnoff, O D., and Menzie, C. (1964). Blood Coagulation, Hemorrhage and Thrombosis, 2nd ed., edited by L. M. Tocantins and L. A. Kazal, P. 224. New York, Grune and Stratton.

Remmert, L. F., and Cohen, P. P. (1949). Fournal of Biological Chemistry, 181, 431.

Shanberge, J. N., Matsuoka, T., and Fukui, H. (1967). American fournal of Clinical Pathology, 47, 533 .

Shaper, A. G., MacIntosh, D. M., and Kyobe, J. (1966). Lancet, 2, 874.

Talbert, L. M., and Langdell, R. D. (1964). American fournal of Obstetrics and Gynecology, 90, 44.

Taylor. E. S. (editor) (1966). In Beck's Obstetrical Practice, 8th ed. p. 188. Baltimore, Williams and Wilkins.

Walker, E. H., and Dormandy, K. M. (1968). Journal of Obstetrics and Gynaecology of the British Commonwealth, 75, 459 .

\title{
Thromboembolic Disease and the Steroidal Content of Oral Contraceptives A Report to the Committee on Safety of Drugs
}

\author{
W. H. W. INMAN,* M.A., M.B., B.CHIR. ; M. P. VESSEY,† M.B., B.S. ; BARBRO WESTERHOLM, $\ddagger$ M.D.
}

\section{A. ENGELUND, $\$ M.P.S.}

Cummary: Reports of thromboembolism following $S$ the use of oral contraceptives received by drug safety committees in the United Kingdom, Sweden, and Denmark have been analysed to investigate possible differences in the risks associated with the various preparations. For this purpose the numbers of reports of thromboembolism attributed to each product were compared with the distribution that would have been expected from market research estimates of sales, assuming that all products carried the same risk.

A positive correlation was found between the dose of oestrogen and the risk of pulmonary embolism, deep vein thrombosis, cerebral thrombosis, and coronary thrombosis in the United Kingdom. A similar association was found for venous thrombosis and pulmonary embolism in Sweden and Denmark. No significant differences could be detected between sequential and combined preparations containing the same doses of oestrogen, nor between the two oestrogens, ethinyloestradiol and mestranol.

Certain discrepancies in the data suggest that the dose of oestrogen may not be the only factor related to the

\footnotetext{
* Senior Medical Officer, Committee on Safety of Drugs, Queen Anne's Mansions, Queen Anne's Gate, London S.W.1.

+ Lecturer in Epidemiology, Department of the Regius Professor of Medicine, The Radcliffe Infirmary, Oxford.

¥ Medical Officer in Charge, Swedish Adverse Drug Reactions Committee, S 104 01, Stockholm 60, Sweden.

5 Pharmaceutical Officer in Charge, Adverse Reactions Board. Danish

National Health Service, Frederikssundsvej 378, DK2700 Brønsh $\phi$, Denmark.
}

risk of thromboembolism; thus there was a significant deficit of reports associated with the combination of mestranol $100 \mu \mathrm{g}$. with norethynodrel $2.5 \mathrm{mg}$. and a significant excess of reports associated with the combination of ethinyloestradiol $50 \mu \mathrm{g}$. with megestrol acetate $4 \mathrm{mg}$. An excess of reports also occurred with other combined preparations containing megestrol acetate.

The data obtained in earlier epidemiological studies were re-examined and, though no trend was obvious in any one of them, the combined results showed an excess of cases of thromboembolism at the highest dose of oestrogen.

The finding of a positive correlation between the dose of oestrogen and the risk of coronary thrombosis is of special interest since previous studies have failed to provide clear evidence of a relationship between oral contraceptives and this condition.

\section{Introduction}

A causal relationship between the use of oral contraceptives and thromboembolic disease was first described in the United Kingdom in a communication to the Medical Research Council in 1967, in which the preliminary results of three studies conducted independently by the Committee on Safety of Drugs, the Medical Research Council's Statistical Research Unit, and the Royal College of General Practitioners were reported. In one of these studies, based on the investigation of deaths due to pulmonary, cerebral, or coron- 